\title{
The use of statins potentiates the insulin sensitizing effect of exercise training in obese males with and without type 2 diabetes
}

Citation for published version (APA):

Meex, R. C., Phielix, E., Schrauwen-Hinderling, V. B., Moonen Kornips, E., Schaart, G., Schrauwen, P., \& Hesselink, M. K. C. (2010). The use of statins potentiates the insulin sensitizing effect of exercise training in obese males with and without type 2 diabetes. Clinical Science, 119(7-8), 293-301.

https://doi.org/10.1042/CS20100153

Document status and date:

Published: 01/10/2010

DOI:

10.1042/CS20100153

Document Version:

Publisher's PDF, also known as Version of record

\section{Document license:}

Taverne

Please check the document version of this publication:

- A submitted manuscript is the version of the article upon submission and before peer-review. There can be important differences between the submitted version and the official published version of record.

People interested in the research are advised to contact the author for the final version of the publication, or visit the DOI to the publisher's website.

- The final author version and the galley proof are versions of the publication after peer review.

- The final published version features the final layout of the paper including the volume, issue and page numbers.

Link to publication

\footnotetext{
General rights rights.

- You may freely distribute the URL identifying the publication in the public portal. please follow below link for the End User Agreement:

www.umlib.nl/taverne-license

Take down policy

If you believe that this document breaches copyright please contact us at:

repository@maastrichtuniversity.nl

providing details and we will investigate your claim.
}

Copyright and moral rights for the publications made accessible in the public portal are retained by the authors and/or other copyright owners and it is a condition of accessing publications that users recognise and abide by the legal requirements associated with these

- Users may download and print one copy of any publication from the public portal for the purpose of private study or research.

- You may not further distribute the material or use it for any profit-making activity or commercial gain

If the publication is distributed under the terms of Article $25 \mathrm{fa}$ of the Dutch Copyright Act, indicated by the "Taverne" license above, 


\title{
The use of statins potentiates the insulin-sensitizing effect of exercise training in obese males with and without Type 2 diabetes
}

\author{
Ruth C. R. MEEX*, Esther PHIELIX $†$, Vera B. SCHRAUWEN-HINDERLING $\dagger$, \\ Esther MOONEN-KORNIPS* $†$, Gert SCHAART*, Patrick SCHRAUWEN $†$ \\ and Matthijs K. C. HESSELINK* \\ *Department of Human Movement Sciences, NUTRIM School for Nutrition, Toxicology and Metabolism, Maastricht University \\ Medical Centre, Maastricht, The Netherlands, †Department of Human Biology, NUTRIM School for Nutrition, Toxicology and \\ Metabolism, Maastricht University Medical Centre, Maastricht, The Netherlands, and $\ddagger$ Department of Radiology, NUTRIM School \\ for Nutrition, Toxicology and Metabolism, Maastricht University Medical Centre, Maastricht, The Netherlands
}

\section{A}

\begin{abstract}
Exercise training is advocated in insulin resistance and statins are used to treat hyperlipidaemia, two cardiometabolic risk factors often presenting concurrently. Statin intake may blunt mitochondrial function and the adaptive response to exercise training. Thus combining exercise training with statin administration may have adverse effects. We examined whether improvements in cardiometabolic risk factors, insulin sensitivity and mitochondrial function mediated by progressive exercise training are affected by statin use. A group of 14 obese elderly males on statins (ST) and 22 matched control subjects (C) were examined. Results on in vivo mitochondrial function [MRS (magnetic resonance spectroscopy)], mitochondrial density (Western blotting), insulin sensitivity (clamp) and metabolic flexibility (indirect calorimetry) were compared before and after a 12-week combined progressive exercise training programme ( $3 \times$ per week; 45 min per session). Except for LDL (low-density lipoprotein) cholesterol, all pre-training values were comparable between statin users and control subjects. In vivo mitochondrial function and mitochondrial density improved by training in both groups. Interestingly, blood-lipid profile, insulin sensitivity $(+72 \%)$, non-oxidative and oxidative glucose disposal $(+38 \%$ and $+112 \%)$ and insulin-mediated suppression of fat oxidation $(-62 \%)$ improved only in the ST group. We conclude that statin treatment did not impede exercise performance or tolerance, mitochondrial function or mass. In addition, traininginduced improvements in glucose homoeostasis were preserved in the ST group. Strikingly, the insulin-sensitizing effect of training was more prominent in the ST group than in the $C$ group. The combined prescription of statins along with exercise training is safe and should be considered for subjects prone to develop insulin resistance.
\end{abstract}

\section{INTRODUCTION}

Hyperlipidaemia and hyperglycaemia are frequently reported in obese subjects and are highly associated with the development of cardiovascular disorders, the primary cause of death in obesity. Whereas treatment with HMG-CoA (3-hydroxy-3-methylglutaryl-CoA) reductase inhibitors, like statins, is often prescribed in

Key words: cardiometabolic risk-factor, exercise training, insulin sensitivity, mitochondrial function, statin, Type 2 diabetes. Abbreviations: AU, arbitrary unit; BMI, body mass index; EGP, endogenous glucose production; $\mathrm{HbA}_{1 \mathrm{c}}$, glycated haemoglobin; HDL, high-density lipoprotein; hsCRP, high-sensitivity C-reactive protein; LDL, low-density lipoprotein; MRS, magnetic resonance spectroscopy; MVC, maximal voluntary contraction; $\mathrm{PCr}$, phosphocreatine; $R \mathrm{a}$, rate of glucose appearance; $R \mathrm{~d}$, rate of glucose disposal; RER, respiratory exchange ratio; T2D, Type 2 diabetes; $\dot{V} \mathrm{CO}_{2}$, carbon dioxide production; $\dot{V} \mathrm{O}_{2}$, oxygen consumption; $\dot{V}_{\mathrm{O}_{2 m a x}}$, maximal $\dot{V}_{\mathrm{O}_{2}}$.

Correspondence: Dr Matthijs K. C. Hesselink (email matthijs.hesselink@bw.unimaas.nl). 
cases of hyperlipidaemia [1,2], implementing routine physical exercise in daily life is advocated in treatment of hyperglycaemia [3]. Hyperlipidaemia and hyperglycaemia, however, often present concurrently. Hence, combining the current guidelines would imply combining statin treatment with physical exercise. Guidelines released recently from the American Diabetes Association state that in diabetic individuals $>40$ years of age, statins use should be added to lifestyle therapy in order to reach target levels of LDL (low-density lipoprotein) cholesterol $<2.6 \mathrm{mmol} / \mathrm{l}$ in patients with T2D (Type 2 diabetes) or $<1.80 \mathrm{mmol} / 1$ in T2D with established CVD (cardiovascular disease) [4]. The use of statins, however, has been associated with myotoxicity, mitochondrial dysfunction [5-9] and muscular damage $[7,10]$. In addition, it has been suggested that statin use may blunt the adaptive response to exercise training $[11,12]$.

To examine the role of statins in exercise-trainingmediated improvements in cardiometabolic risk factors, markers of in vivo mitochondrial function and insulin sensitivity were evaluated after 12 weeks of training in a group of elderly male obese healthy and T2D subjects, stratified to the use of statins.

\section{MATERIALS AND METHODS}

\section{Subject recruitment and stratification}

Initially, we recruited 38 sedentary elderly male obese subjects, of whom 18 subjects had been diagnosed with T2D for at least one year [13]. Diabetic patients had well-controlled diabetes $\left[\mathrm{HbA}_{1 \mathrm{c}}\right.$ (glycated haemoglobin) $= \pm 7.2 \%]$ and were using oral antidiabetic agents [metformin only, or in combination with SU (sulfonylurea) derivatives]. The other 20 subjects were categorized as normoglycaemic. Glycaemic control was checked for by measuring $\mathrm{HbA}_{1 \mathrm{c}}$, and glucose tolerance by performing an oral glucose tolerance test. Subjects were informed about the nature and risks of the experimental procedures before their written informed consent was obtained. The study has been carried out in accordance with the Declaration of Helsinki (2000) of the World Medical Association and was approved by the institutional medical ethical committee.

Retrospectively, the entire group of 38 subjects was stratified according to the use of statins. Two subjects on fibrates were excluded from the analysis. Statin use was defined as using any type of statins for over a year at the onset of the study, irrespective of dosage. Individual data on statin use can be found in the Supplementary Table S1 at http://www.clinsci.org/cs/119/cs1190293add.htm. Stratification resulted in 14 subjects on statins (ST group) and 22 subjects without statin treatment ( $\mathrm{C}$ group) with eight T2D subjects in both groups. None of the baseline characteristics was significantly different between the
C and ST groups, except for LDL cholesterol which was lower in the patients using statins (Table 1). To examine whether the type of statin and the dosage used may have affected the outcome of the present study, we ranked the statins on their reported LDL lowering potency, taking into account the dosage used. Using this marker of potency as an independent variable we performed correlative analysis with all parameters under investigation.

\section{Exercise training protocol}

All subjects were engaged in an exercise programme for 12 weeks, consisting of a combination of aerobic and resistance exercise. Subjects were monitored extensively during the training period and attention has been paid to follow up conversations with respect to their motivation. Aerobic exercise was carried out on a cycling ergometer twice a week for $30 \mathrm{~min}$ at $55 \%$ of their previously determined maximal work load. Training sessions took place in small groups of 3-4 persons and, as a measure of exercise intensity, heart rate was monitored and registered in a training diary at $5 \mathrm{~min}$ intervals. Maximal workload was re-evaluated after 6 weeks of training and training load was adjusted accordingly.

Resistance exercise was performed once a week for $40 \mathrm{~min}$. The training involved a 'circuit' of eight exercises, focussing on large muscle groups (i.e. chest press, leg extension, latissimus dorsi pull down, leg press, triceps curl, biceps curl, crunches and horizontal row). A first series of eight repetitions was performed at $55 \%$ of their pre-determined MVC (maximal voluntary contraction), followed by two series of eight repetitions at $75 \%$ MVC [13]. Resistance training was given individually and MVC was re-assessed every 4 weeks.

\section{Hyperinsulinaemic-euglycaemic clamp}

Dietary habits were stable, physical exercise was avoided for the 2 days prior to the clamp procedure and anti-diabetic medication was withdrawn 7 days prior to the clamp. The use of statins was continued throughout the study. Insulin sensitivity was measured by a $3 \mathrm{~h}$ hyperinsulinaemic-euglycaemic clamp, before and after the training period. A primed constant infusion of glucose tracer $\left(\left[6,6-{ }^{2} \mathrm{H}_{2}\right]\right.$ glucose $)$ was initiated at $t=0 \mathrm{~min}$ to determine non-insulin stimulated $R$ a (rate of glucose appearance) and $R \mathrm{~d}$ (rate of glucose disposal). At $t=180 \mathrm{~min}$, the actual clamp procedure was started with a primed constant infusion of insulin $(40 \mathrm{~m}$ units $\cdot \mathrm{m}^{-2} \cdot \min ^{-1}$ ) [13]. EGP (endogenous glucose production) was calculated as $R$ a minus exogenous glucose infusion rate. Non-oxidative glucose disposal was calculated as $R \mathrm{~d}$ minus carbohydrate oxidation. In the non-insulin-stimulated period ( $t=150-180 \mathrm{~min})$ and under steady clamp conditions $(t=330-360 \mathrm{~min}$ ), blood samples and indirect calorimetry measurements (ventilated hood) were obtained. A needle muscle biopsy 
Table I Subject characteristics

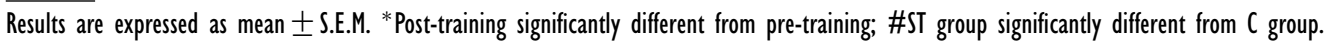

\begin{tabular}{|c|c|c|c|c|}
\hline \multirow[b]{2}{*}{ Subject characteristics } & \multicolumn{2}{|l|}{ C group } & \multicolumn{2}{|l|}{ ST group } \\
\hline & Pre-training & Post-training & Pre-training & Post-training \\
\hline Age (years) & $59.2 \pm 1.0$ & & $58.4 \pm 0.9$ & \\
\hline Subjects diagnosed with diabetes $(n)$ & 8 & & 8 & \\
\hline Weight (kg) & $94.9 \pm 2.8$ & $94.4 \pm 2.9$ & $93.2 \pm 3.2$ & $91.9 \pm 3.1$ \\
\hline Height $(\mathrm{cm})$ & $177.6 \pm 1.3$ & & $177.2 \pm 1.5$ & \\
\hline BMI $\left(\mathrm{kg} \cdot \mathrm{m}^{-2}\right)$ & $30.1 \pm 0.8$ & $30.0 \pm 0.9$ & $30.0 \pm 0.9$ & $29.6 \pm 0.8$ \\
\hline Body fat $(\%)$ & $32.4 \pm 1.3$ & $31.6 \pm 1.3^{*}$ & $29.6 \pm 1.8$ & $28.4 \pm 1.8$ \\
\hline Fat mass $(\mathrm{kg})$ & $31.2 \pm 1.8$ & $30.4 \pm 1.8^{*}$ & $27.9 \pm 2.3$ & $26.4 \pm 2.2$ \\
\hline Fat-free mass (kg) & $64.5 \pm 1.9$ & $64.9 \pm 1.9$ & $65.3 \pm 2.1$ & $65.5 \pm 2.1$ \\
\hline$\dot{V}_{0_{2}}$ & $28.6 \pm 1.1$ & $30.5 \pm 1.2^{*}$ & $28.5 \pm 1.4$ & $31.7 \pm 1.7^{*}$ \\
\hline Work max. (Watt) & $208 \pm 9$ & $236 \pm 9^{*}$ & $201 \pm 10$ & $231 \pm 10^{*}$ \\
\hline Average strength $(\mathrm{kg})$ & $83.5 \pm 3.2$ & $102.9 \pm 3.7^{*}$ & $87.4 \pm 4.0$ & $105.3 \pm 4.4^{*}$ \\
\hline Fasting glucose (mmol/l) & $7.2 \pm 0.4$ & $6.9 \pm 0.4$ & $7.5 \pm 0.5$ & $7.3 \pm 0.6$ \\
\hline $\mathrm{HbA}_{\mathrm{lc}}(\%)$ & $6.4 \pm 0.2$ & $6.3 \pm 0.2$ & $6.6 \pm 0.3$ & $6.7 \pm 0.3$ \\
\hline Triacylglycerols (mmol/l) & $1.6 \pm 0.1$ & $1.6 \pm 0.2$ & $1.7 \pm 0.2$ & $1.6 \pm 0.1$ \\
\hline Total cholesterol (mmol/l) & $5.4 \pm 0.1$ & $5.2 \pm 0.2$ & $5.0 \pm 0.2$ & $4.6 \pm 0.2^{*}$ \\
\hline LDL (mmol/l) & $3.5 \pm 0.1$ & $3.3 \pm 0.2$ & $2.9 \pm 0.2 \#$ & $2.7 \pm 0.2 \#$ \\
\hline HDL (mmol/l) & $1.2 \pm 0.0$ & $1.2 \pm 0.1$ & $1.3 \pm 0.1$ & $1.3 \pm 0.1$ \\
\hline hsCRP (mg/l) & $2.0 \pm 0.3$ & $1.8 \pm 0.3$ & $1.6 \pm 0.5$ & $1.6 \pm 0.5$ \\
\hline
\end{tabular}

was obtained from the vastus lateralis muscle before starting the tracer infusion.

\section{Blood sample analysis}

Blood was sampled and analysed as described previously [13]. Concentrations of total cholesterol (ABX Diagnostics), HDL (high-density lipoprotein) cholesterol (precipitation method; Roche Diagnostics), and triacylglycerols (triglycerides) corrected for free glycerol (Sigma-Aldrich) were analysed enzymatically. Serum LDL cholesterol concentrations were calculated by using the formula of Friedewald. hsCRP (highsensitivity C-reactive protein) was measured on a Roche Cobas Mira random access biochemistry analyser with a commercially available kit (Kamiya Biomedical Company).

\section{Metabolic flexibility}

Metabolic flexibility is the ability to switch from predominantly fat oxidation in the fasted state to glucose oxidation under insulin-stimulated conditions [14]. Metabolic flexibility was expressed as the change in RER (respiratory exchange ratio) from the fasted state to the insulin-stimulated condition. Substrate oxidation was calculated according to the method of Frayn [15] with protein oxidation considered negligible: carbohydrate oxidation rate $\left(\mu \mathrm{mol} \cdot \mathrm{kg}^{-1}\right.$ of body weight $\left.\cdot \min ^{-1}\right)=\left(4585 \times \dot{V} \mathrm{CO}_{2}\right)-\left(3226 \times \dot{V}_{\mathrm{O}_{2}}\right) /$ body weight/ $180 \times 1000$; where $\dot{V} \mathrm{CO}_{2}$ is carbon dioxide production and $\dot{V}_{2}$ is oxygen consumption) and lipid oxidation rate $\left(\mu \mathrm{mol} \cdot \mathrm{kg}^{-1}\right.$ of body weight $\left.\cdot \mathrm{min}^{-1}\right)=$ $\left(1695 \times \dot{V} \mathrm{O}_{2}-1701 \times \dot{V} \mathrm{CO}_{2}\right) /$ body $\quad$ weight $/ 860 \times 1000$ [15].

\section{MRS (magnetic resonance spectroscopy)- based measurement of mitochondrial function}

Maximal muscle strength during one-legged kneeextension exercise was assessed a few days prior to the actual ${ }^{31} \mathrm{P}$-MRS measurement with an incremental protocol in an MRS compatible exercise device. During this test subjects were asked to perform knee-extensions at $0.5 \mathrm{~Hz}$, while increasing the load to be lifted every $30 \mathrm{~s}$ by $500 \mathrm{~g}$, with an initial weight of $5 \mathrm{~kg}$. The test was performed until exhaustion or until the frequency of $0.5 \mathrm{~Hz}$ could no longer be maintained (maximal load). The PCr (phosphocreatine)-lowering exercise session during the test-day was performed at $60 \%$ of this predetermined load.

Baseline ${ }^{31} \mathrm{P}-\mathrm{MRS}$ measurements were performed on a 1.5 T whole-body scanner (Intera; Philips Health Care). A 6-cm surface coil was used for localization and was fixed in the middle of the vastus lateralis muscle. A series of partially saturated spectra (free induction decays) was acquired (TR $=4 \mathrm{~s} ; 1$ measurement; spectral bandwidth $1500 \mathrm{~Hz}$; adiabatic pulse). Knee extension exercise was performed at $0.5 \mathrm{~Hz}$ to an acoustic cue on a home-built magnetic resonance compatible ergometer with a pulley system. The PCr-lowering exercise was performed with identical weights before and after training. 
The acquisition time during the time series was structured as follows: 40 s of rest, 5 min of knee-extension exercise and $5 \mathrm{~min}$ of recovery. After application of phase correction, line-broadening and DC (direct conversion) correction, spectra were fitted in the time domain with the AMARES algorithm [16] in the jMRUI software [17] using prior knowledge. Five peaks were fitted with Gaussian curves ( $P_{i}, P C r$, and 3 ATP peaks) in the partially saturated spectra of the time series. To determine the $\mathrm{pH}$ during the exercise period, five consecutive spectra of the time series were added and the $\mathrm{pH}$ was calculated in jMRUI from the frequency shift between the PCr and $\mathrm{P}_{\mathrm{i}}$ peaks. The time-course of the $\mathrm{PCr}$ amplitude $[\mathrm{PCr}(t)]$ during the last $20 \mathrm{~s}$ of exercise (steady state) and during the recovery period was fitted with MATLAB software (Mathworks) as described previously [18], asssuming a mono-exponential PCr recovery. Post-exercise PCr resynthesis rate is an almost exclusively oxidative process and is hence a good reflection of mitochondrial oxidative function. The rate constant of the monoexponential recovery is given. The higher the rate constant $\left(\mathrm{s}^{-1}\right)$, the better in vivo mitochondrial function.

\section{Mitochondrial density}

Five different structural components of the electron transport chain were measured at the protein level as a reflection of mitochondrial density [13]. The ND6 subunit of complex I, the $30-\mathrm{kDa}$ Ip subunit of complex II, the $47-\mathrm{kDa}$ core protein 2 of complex III, COXII (cytochrome $c$ oxidase subunit II) and the the $\mathrm{F}_{\mathrm{o}} \mathrm{F}_{1}$ ATP synthase subunit (complex V) were measured using a monoclonal antibody cocktail of five monoclonal antibodies directed against the subunits mentioned (MitoSciences) as previously described [19]. As these subunits differ considerably in molecular mass, this antibody gives five distinct bands in human samples. Each individual band reflects one of the mitochondrial subunits. In short, muscle biopsies were homogenized in ice-cold Tris/EDTA buffer at $\mathrm{pH} 7.4$, and then the homogenates were sonicated for $15 \mathrm{~s}$. Subsequently, two volumes of each skeletal muscle homogenate and one volume of SDS sample buffer were boiled for $4 \mathrm{~min}$. Next, $13 \%$ polyacrylamide gels containing $0.1 \%$ SDS were loaded with equal amounts of protein from each sample, and electrophoresis was performed using a Mini-Protean 3 Electrophoresis Cell (Bio-Rad Laboratories). After electrophoresis, the gel was scanned and then subjected to densitometry analysis for all of the individual bands (per subject per subunit). To adjust for inter-gel variation, the densitometry of the band of interest per subject was normalized to the mean densitometry of the complete gel. Protein content is expressed as AUs (arbitrary units).

\section{Statistics}

Statistical analyses were performed two-sided using SPSS for Windows 15.0 software (SPSS). Statistical significance was set at $P<0.05$. A two-way ANOVA model for repeated measures was applied using control and statin users as between subject variables and pre- and post-training data as repeated within subject variables. Differential responses between the ST and C groups were examined using the interaction terms. In addition, in the case of a significant training effect, differential responses of T2D and healthy subjects within the ST and C groups were examined.

\section{RESULTS}

\section{Subjects}

Before training, body weight $(94.9 \pm 2.8$ and $93.2 \pm$ $3.2 \mathrm{~kg}), \mathrm{BMI}$ (body mass index) $(30.1 \pm 0.8$ and $30.0 \pm$ $\left.0.9 \mathrm{~kg} \cdot \mathrm{m}^{-2}\right)$, and age $(59.2 \pm 1.0$ and $58.4 \pm 0.9$ years $)$ were comparable in the $\mathrm{C}$ and ST groups respectively. Training did not alter body weight and BMI in the $\mathrm{C}$ group, whereas body weight, but not BMI, tended to decline in the ST group (from $93.2 \pm 3.2$ to $91.9 \pm 3.1 \mathrm{~kg}$, $P=0.09$, and from $30.0 \pm 0.9$ to $29.6 \pm 0.8 \mathrm{~kg} \cdot \mathrm{m}^{-2}$ respectively). Fat mass declined in the $\mathrm{C}$ group (from $31.2 \pm 1.8$ to $30.4 \pm 1.8 \mathrm{~kg}$ after training, $P=0.02$ ), whereas there was a tendency towards a decreased fat mass in the ST group (from $27.9 \pm 2.3$ to $26.4 \pm 2.2 \mathrm{~kg}$ after training; $P=0.10)$. Fat-free mass was similar between both groups and was unaffected by training.

Before training, $\dot{V}_{\mathrm{O}_{2 \max }}$ (maximal $\dot{V}_{\mathrm{O}_{2}}$ ) and maximal workload was comparable in both groups $\left(\dot{V}_{\mathrm{O}_{2 \max }}\right.$ of $28.6 \pm 1.0 \mathrm{ml} \cdot \mathrm{kg}^{-1}$ of body weight $\cdot \mathrm{min}^{-1}$ and $27.7 \pm 1.5 \mathrm{ml} \cdot \mathrm{kg}^{-1}$ of body weight $\cdot \mathrm{min}^{-1}$ in the $\mathrm{C}$ and ST groups respectively, $P=0.63$; workload, $208 \pm 9 \mathrm{~W}$ and $201 \pm 10 \mathrm{~W}$ in the $\mathrm{C}$ and ST groups respectively, $P=0.61)$. Exercise training improved $\dot{V}_{2 \max }$ and maximal workload significantly and to the same extent in the $\mathrm{C}$ and ST groups $\left(\dot{V}_{\mathrm{O}_{2 \max }}\right.$ by $+7.0 \pm 2.2 \%$ and $+11.7 \pm 3.2 \%$ in the $\mathrm{C}$ and ST groups respectively, $P<0.01$; workload by $+14.6 \pm 2.7 \%$ and $+16.1 \pm 2.3 \%$ in the $\mathrm{C}$ and ST groups respectively, $P<0.01)$. Muscle strength was comparable before training $(83.5 \pm 3.2 \mathrm{~kg}$ and $87.4 \pm 4.0 \mathrm{~kg}$ in the $\mathrm{C}$ and ST groups respectively, $P=0.46)$ and improved significantly and to the same extent in both groups $(+24.7 \pm 1.9 \%$ and $+21.6 \pm 2.1 \%$ in the $\mathrm{C}$ and ST groups respectively, $P<0.01)$. On the rare occasion of missing a training session, this session was rescheduled within a week of the original training date. As maximally achieved workload during the maximal test was similar in both groups and the number of training sessions performed was identical, total workload performed during the training sessions across groups was comparable.

\section{Glucose and insulin profile}

Fasting glucose levels (of $7.2 \pm 0.4 \mathrm{mmol} / \mathrm{l}$ and $7.5 \pm$ $0.5 \mathrm{mmol} / \mathrm{l}$ in the $\mathrm{C}$ and ST groups respectively) and 
$\mathrm{HbA}_{1 \mathrm{c}}$ levels (of $6.4 \pm 0.2 \%$ and $6.6 \pm 0.3 \%$ in the $\mathrm{C}$ and ST groups respectively) were similar at the onset of the training programme. The $12-$ week exercise training programme did not change $\mathrm{HbA}_{1 \mathrm{c}}$ or fasting glucose levels in either group. Fasting plasma insulin levels did not differ significantly before onset of the training programme between the $\mathrm{C}$ and ST groups (17.2 \pm 2.0 compared with $17.9 \pm 2.0 \mathrm{~m}$-units/l in the $\mathrm{C}$ and ST groups respectively) but decreased significantly in both groups after training (from $17.2 \pm 2.0 \mathrm{~m}$-units/l to $15.7 \pm 1.7 \mathrm{~m}$-units/l in the $\mathrm{C}$ group and from $17.9 \pm 2.0 \mathrm{~m}$-units/ 1 to $15.0 \pm 1.7 \mathrm{~m}$ units/ 1 in the ST group, $P<0.05$ in both groups).

\section{Lipid profile}

Pre-training, insulin-mediated suppression of lipolysis, measured as the drop in plasma non-esterified fatty acid upon insulin infusion, was comparable between groups. Training did not affect insulin-mediated suppression of lipolysis in the $\mathrm{C}$ group (suppression pre-training $81.7 \pm 1.6 \%$ compared with $83.0 \pm 1.5 \%$ post-training), but improved significantly in the ST group (from $77.7 \pm 1.8 \%$ to $82.9 \pm 1.7 \%, P=0.01)$.

Triacylglycerols were comparable between groups and were unaffected by training. Also total cholesterol before training was similar in the C and ST groups. Training reduced total cholesterol significantly in the ST group (from $5.0 \pm 0.2$ to $4.6 \pm 0.2 \mathrm{mmol} / \mathrm{l}, P=0.03$ ), but not in the $C$ group (from $5.4 \pm 0.2$ to $5.2 \pm 0.1 \mathrm{mmol} / \mathrm{l}$ ), resulting in a tendency towards lower total cholesterol values in the ST group compared with the $\mathrm{C}$ group $(P=0.07)$. LDL cholesterol was significantly higher in the $\mathrm{C}$ group compared with the ST group pre-training $(3.5 \pm 0.1 \mathrm{mmol} / 1$ compared with $2.9 \pm 0.2 \mathrm{mmol} / 1$ in the $\mathrm{C}$ and ST groups respectively, $P=0.05)$ and tended to decline in both groups (from $3.5 \pm 0.1$ to $3.3 \pm 0.2 \mathrm{mmol} / \mathrm{l}$ in the $\mathrm{C}$ group, $P=0.07$, and from $2.9 \pm 0.2$ to $2.7 \pm 0.2 \mathrm{mmol} / 1$ in the ST group, $P=0.07$ ). HDL cholesterol and hsCRP was comparable in the $\mathrm{C}$ and ST groups and was unaffected by training (Table 1).

\section{Whole-body insulin-stimulated glucose uptake}

Insulin-stimulated glucose uptake, as determined by the change in the glucose disposal rate during the hyperinsulinaemic-euglycaemic clamp $(\Delta R \mathrm{~d})$, was not different between the $\mathrm{C}$ and ST groups pre-training $(12.7 \pm 2.1$ and $9.5 \pm 2.5 \mu \mathrm{mol} \cdot \mathrm{kg}^{-1}$ of body weight $\cdot \mathrm{min}^{-1}$ in the $\mathrm{C}$ and ST groups, $P=0.33$ ). The $\mathrm{C}$ and ST groups responded differentially to training as indicated by significant interaction $(P<0.01) . \Delta R \mathrm{~d}$ did not change after training in the $C$ group (from $12.7 \pm 2.1$ to $13.6 \pm 1.9 \mu \mathrm{mol} \cdot \mathrm{kg}^{-1}$ of body weight $\left.\cdot \min ^{-1}\right)$, but improved significantly in the ST group (from $9.5 \pm 2.5$ to $16.3 \pm 2.3 \mu \mathrm{mol} \cdot \mathrm{kg}^{-1}$ of body weight $\left.\cdot \mathrm{min}^{-1}, P<0.01\right)$. Non-oxidative glucose disposal (from $4.7 \pm 2.1$ to $10.0 \pm 2.1 \mu \mathrm{mol} \cdot \mathrm{kg}^{-1}$ of body weight $\left.\cdot \min ^{-1}, P<0.01\right)$, as well as oxidative glucose disposal (from $4.7 \pm 0.9$ to $6.5 \pm 0.7 \mu \mathrm{mol} \cdot \mathrm{kg}^{-1}$ of body weight $\left.\cdot \min ^{-1}, P<0.01\right)$ improved significantly in the ST group upon training, but did not change in the C group (with a significant interaction effect between groups for non-oxidative glucose disposal; $P<0.01$ ) (Table 2). Insulin-mediated suppression of endogenous glucose production $(\Delta \mathrm{EGP})$ was comparable pretraining $\left(-6.8 \pm 0.8\right.$ and $-7.1 \pm 1.5 \mu \mathrm{mol} \cdot \mathrm{kg}^{-1}$ of body weight $\cdot \min ^{-1}$ in the $\mathrm{C}$ and ST groups respectively) and was not significantly affected by training, despite a significant interaction effect (Table 2). Results on insulin and glucose disposal are presented in Table 2.

\section{Markers of mitochondrial density}

Mitochondrial density was evaluated by measuring the levels (protein content) of five structural subunits of the distinct complexes of the electron transport chain. Neither the individual complexes, nor the mean protein content of these complexes revealed a difference in mitochondrial density between the $\mathrm{C}$ and ST groups pre-training $(0.56 \pm 0.10$ and $0.71 \pm 0.10 \mathrm{AU}$ in the $\mathrm{C}$ and ST groups respectively, not significant). Training resulted in increased mitochondrial density in both groups after training (C group, $P<0.01$; ST group, $P=0.03$ ) (Figure 1A).

\section{MRS measurement}

Pre-training in vivo mitochondrial function in the $\mathrm{C}$ group was similar to the ST group (rate constant of $0.034 \pm 0.002$ and $0.034 \pm 0.003 \mathrm{~s}^{-1}$ in the C and ST groups respectively), whereas after training in vivo mitochondrial function improved $34 \%$ and $46 \%$ (C group, $P<0.01$; ST group, $P=0.02$ ) (Figure $1 \mathrm{~B}$ ).

\section{Metabolic flexibility}

Prior to training, metabolic flexibility $(P=0.51)$, insulin-stimulated glucose oxidation ( $\Delta$ carbohydrate oxidation, $P=0.99)$ and suppressed fat oxidation $(\Delta \mathrm{Fat}$ oxidation, $P=0.47$ ) was comparable between the $C$ and ST groups (Figures 1C and 1D). Exercise training did not affect metabolic flexibility in the $\mathrm{C}$ group $(\triangle \mathrm{RER}$ from $0.071 \pm 0.008$ to $0.083 \pm 0.011, P=0.22$ ), whereas metabolic flexibility improved significantly in the ST group ( $\triangle$ RER from $0.062 \pm 0.012$ to $0.089 \pm 0.008$, $P=0.01)$, reflecting a concomitant increase in insulinstimulated glucose oxidation $(P=0.01)$ (Figure $1 \mathrm{C}$ ) and suppression of fat oxidation $(P=0.01)$ (Figure 1D).

\section{DISCUSSION}

We examined the effect of exercise training on cardiometabolic risk factors, markers of in vivo mitochondrial function and insulin sensitivity in male obese elderly with and without T2D who were on 
Table 2 Substrate kinetics pre- and post-training

Results are expressed as means \pm S.E.M. *Post-training significantly different from pre-training; $\S$ significant interaction effect between $C$ and ST groups. NOGD, non-oxidative glucose disposal.

\begin{tabular}{|c|c|c|c|c|}
\hline \multirow[b]{2}{*}{ Substrate } & \multicolumn{2}{|l|}{ C group } & \multicolumn{2}{|l|}{ ST group } \\
\hline & Pre-training & Post-training & Pre-training & Post-training \\
\hline \multicolumn{5}{|c|}{ Plasma insulin (m-units/l) } \\
\hline Basal & $17.2 \pm 2.0$ & $15.7 \pm 1.7^{*}$ & $17.9 \pm 2.0$ & $15.0 \pm 1.7^{*}$ \\
\hline Clamp & $109.4 \pm 5.4$ & $107.8 \pm 4.2$ & $1 \mathrm{II} .2 \pm 4.5$ & $107.9 \pm 5.1$ \\
\hline \multicolumn{5}{|c|}{ Plasma non-esterified fatty acid $(\mu \mathrm{mol} / \mathrm{l})$} \\
\hline Basal & $498.6 \pm 18.3$ & $498.7 \pm 31.1$ & $473.3 \pm 31.0$ & $421.4 \pm 27.9$ \\
\hline Clamp & $90.2 \pm 7.7$ & $81.5 \pm 8.2$ & $103.9 \pm 10.0$ & $71.1 \pm 8.3^{*} \S$ \\
\hline \multicolumn{5}{|c|}{$R d$ glucose $\left(\mu \mathrm{mol} \cdot \mathrm{kg}^{-1}\right.$ of body weight $\left.\cdot \min ^{-1}\right)$} \\
\hline Basal & $10.0 \pm 0.8$ & $8.7 \pm 0.7$ & $10.9 \pm 0.9$ & $8.7 \pm 0.7^{*}$ \\
\hline Clamp & $22.7 \pm 2.0$ & $22.3 \pm 2.1$ & $20.3 \pm 2.2$ & $25.0 \pm 2.1^{*} \S$ \\
\hline Delta & $12.7 \pm 2.1$ & $13.6 \pm 1.9$ & $9.5 \pm 2.5$ & $16.3 \pm 2.3^{*} \S$ \\
\hline \multicolumn{5}{|c|}{$\operatorname{EGP}\left(\mu \mathrm{mol} \cdot \mathrm{kg}^{-1}\right.$ of body weight $\left.\cdot \mathrm{min}^{-1}\right)$} \\
\hline Basal & $9.7 \pm 0.6$ & $9.3 \pm 0.6$ & $9.7 \pm 0.7$ & $7.9 \pm 0.8$ \\
\hline Clamp & $2.8 \pm 0.4$ & $0.8 \pm 0.5^{*}$ & $2.7 \pm 1.0$ & $1.8 \pm 1.3$ \\
\hline Delta & $-6.8 \pm 0.8$ & $-8.5 \pm 0.7$ & $-7.1 \pm 1.5$ & $-6.5 \pm 1.5 \S$ \\
\hline \multicolumn{5}{|c|}{ Carbohydrate oxidation $\left(\mu \mathrm{mol} \cdot \mathrm{kg}^{-1}\right.$ of body weight $\left.\cdot \mathrm{min}^{-1}\right)$} \\
\hline Basal & $6.8 \pm 0.5$ & $7.3 \pm 0.5$ & $7.8 \pm 0.8$ & $7.0 \pm 0.5$ \\
\hline Clamp & $11.5 \pm 0.7$ & $12.9 \pm 0.8$ & $12.6 \pm 1.1$ & $13.5 \pm 0.7$ \\
\hline Delta & $4.7 \pm 0.7$ & $5.2 \pm 0.8$ & $4.7 \pm 0.9$ & $6.5 \pm 0.7^{*}$ \\
\hline \multicolumn{5}{|c|}{ NOGD $\left(\mu \mathrm{mol} \cdot \mathrm{kg}^{-1}\right.$ of body weight $\left.\cdot \mathrm{min}^{-1}\right)$} \\
\hline Basal & $3.3 \pm 0.8$ & $1.2 \pm 0.6^{*}$ & $3.0 \pm 1.0$ & $1.8 \pm 1.1$ \\
\hline Clamp & $11.2 \pm 1.5$ & $9.5 \pm 1.8$ & $7.8 \pm 1.9$ & $11.9 \pm 2 .{ }^{*} \S$ \\
\hline Delta & $7.9 \pm 1.7$ & $8.4 \pm 1.7$ & $4.7 \pm 2.1$ & $10.0 \pm 2.1 * \S$ \\
\hline \multicolumn{5}{|c|}{ Lipid oxidation $\left(\mu \mathrm{mol} \cdot \mathrm{kg}^{-1}\right.$ of body weight $\left.\cdot \mathrm{min}^{-1}\right)$} \\
\hline Basal & $1.10 \pm 0.06$ & $1.02 \pm 0.04^{*}$ & $1.06 \pm 0.05$ & $1.15 \pm 0.08$ \\
\hline Clamp & $0.69 \pm 0.04$ & $0.57 \pm 0.06^{*}$ & $0.71 \pm 0.06$ & $0.60 \pm 0.04$ \\
\hline Delta & $-0.41 \pm 0.05$ & $-0.45 \pm 0.07$ & $-0.34 \pm 0.07$ & $-0.55 \pm 0.06^{*}$ \\
\hline
\end{tabular}

lipid-lowering drugs (statins, ST group) and compared these effects with a control group (C group) not taking statins.

Maximal exercise capacity and markers of mitochondrial content and function were not negatively impacted by statins. In addition, training-induced improvements in markers of cardiometabolic risk, insulin sensitivity and fuel selection were more prominent, and sometimes even exclusively detectable in the ST group compared with the C group. Exercise-training-mediated improvements in mitochondrial density and function were as prominent in the ST group as in the C group. The present study hence shows that exercise prescription on top of statin treatment is safe and at least as beneficial, and for some parameters even more beneficial, for cardiometabolic health, glucose homoeostasis and mitochondrial function than exercise training without statins.

We did not find correlations between statin potency and other parameters, suggesting that the findings do not scale with the dosage or potency of the statin used. Furthermore, no interaction effects were detected between healthy subjects and diabetic subjects, indicating that differences were not solely specific to healthy or diabetic subjects.

\section{Pre-training pleiotropic effects of statins}

After stratification to the use of statins, both groups were comparable for all subject characteristics, except for LDL cholesterol (Table 1). In addition, markers for insulin sensitivity, substrate metabolism and mitochondrial function were similar (Table 2). Interestingly, this is in contrast with previous studies in rodents $[20,21]$ and humans [22], showing improved insulin-sensitivity on a whole-body level and in liver. Another study reported a decrease in mtDNA (mitochondrial DNA) copy number [8], suggesting that statins may affect these parameters somehow. In a more recent study, however, a high dose of statins $(80 \mathrm{mg} /$ day simvastatin) did not affect insulin-mediated glucose disposal, hepatic glucose production and myocellular lipid deposition [23]. 

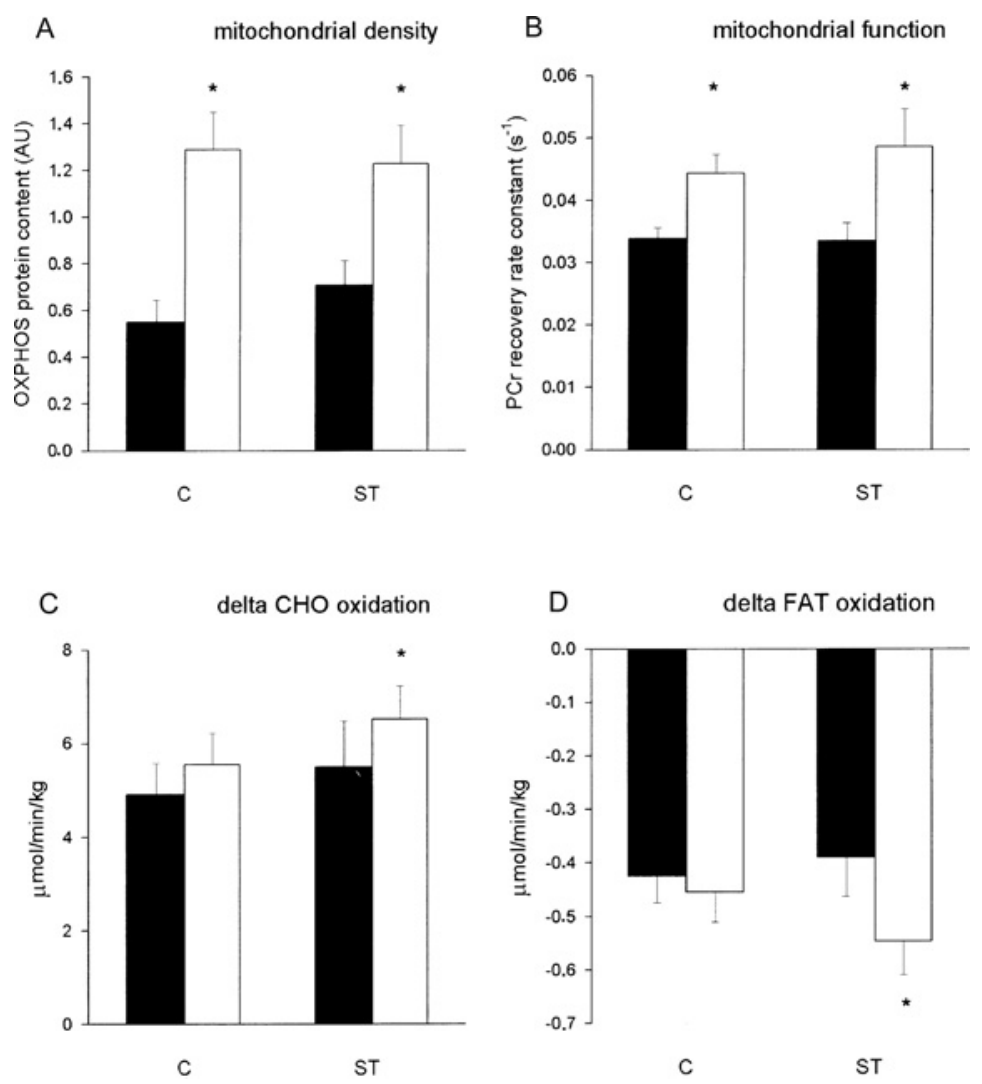

Figure I Mitochondrial density and function, and metabolic flexibility in ST and C groups

(A) Mitochondrial density as determined from the mean of five different structural components of the electron transport chain, measured at the protein level, before (black bars) and after (white bars) training. (B) In vivo mitochondrial function as determined by post-exercise $\mathrm{PCr}$ recovery rate as described previously [18], before (black bars) and after (white bars) training. Results are expressed as rate constant $\left(\mathrm{s}^{-1}\right)$. A higher rate constant corresponds to a high in vivo mitochondrial function. ( $C$ and D) $\Delta$ carbohydrate ( $\mathrm{CHO}$ ) oxidation and $\Delta$ fat oxidation, measured as the change from the fasted state to the insulin-stimulated state, before (black bars) and after (white bars) training. Results are expressed as means \pm S.E.M., * post-training significantly different from pre-training.

\section{Exercise tolerance on statins}

Classical measures of physical fitness were similar in the $\mathrm{C}$ and ST groups, which is in line with previous reports [24]. A 12-week interval cycling training programme combined with resistance exercise did not provoke statinrelated muscle pain or stiffness and was equally welltolerated in the C and ST groups. Self-reported musclestiffness due to unfamiliar exercise occurred predominantly in the first 1.5 weeks and rapidly disappeared after familiarization with the exercise programme. Trainingmediated improvements in exercise capacity were similar in both groups. Hence, the results of the present study do not support the hypothesis that the use of statins provokes muscle pathology or may blunt the adaptive responses to exercise training, as suggested previously [25]. However, the present study applied a tailored progressive exercise training programme to avoid the development of muscle soreness, whereas other investigations applied eccentric exercise and exercise bouts on maximal intensity $[11,12]$, types of exercise prone to the development of muscle soreness. In addition, none of the ST group sub- jects in the present study reported muscle-related complaints under resting conditions after starting their statin treatment. We can hence not exclude that the subjects in the present study represent a statin-tolerating subgroup and that this may contribute to the fact that none of them experienced muscle-related problems while exercising.

\section{Post-training pleiotropic effects of statins}

In contrast with previous reports in humans [6] we did not detect any (negative) effects of statin use on mitochondrial content and function pre-training and showed similar improvements upon training. It should be noted though, that in the present study the dosage of statins used was in general lower [6].

Intriguingly, exercise training in the ST group improved insulin-stimulated glucose disposal, both by an increase in oxidative, as well as in non-oxidative, glucose disposal, without an effect on hepatic insulin sensitivity. The improvement in non-oxidative glucose disposal is of particular interest, as we previously identified non-oxidative glucose disposal as the non-responsive 
culprit for training-mediated improvements in T2D patients [13]. In contrast, in the C group, insulinstimulated non-oxidative glucose disposal did not improve significantly after training.

One of the characteristics of insulin-resistant muscle is metabolic inflexibility ( $\triangle \mathrm{RER}$ ). In the present study we observed that metabolic flexibility improved upon training in the ST group, indicating that statin use does not interfere with training-induced metabolic improvements. The improvement in metabolic flexibility was less pronounced (and non-significant) in the $\mathrm{C}$ group.

\section{Putative mechanisms of statin-mediated potentiation of the beneficial effect of exercise training}

We strikingly observed that the insulin-sensitizing effects of exercise training were potentiated by the use of statins, but the precise mechanism(s) remains to be established. Candidate mechanisms include a statin-mediated reduction in superoxide-induced cell damage [26], statinmediated reduction of low-grade inflammation [27] or a reduction in non-esterified fatty acid flux and hepatic fat storage [28] resulting in improved hepatic insulin sensitivity. The present study does not allow conclusions on the putative effects of statins on superoxide production or superoxide-mediated cell damage. Using hsCRP as a marker for low-grade inflammation, we report no differences in low-grade inflammation pre-training between the $\mathrm{C}$ and ST groups, and did not detect any training effects on hsCRP. Recently it has been shown that even a high-dose of simvastatin ( $80 \mathrm{mg}$ daily) does not affect hepatic lipid stores or insulin sensitivity significantly [23]. This is in line with the present study showing similar insulin-mediated suppression of hepatic glucose output pre-training in the $\mathrm{C}$ and ST groups.

Many patients taking statins are also taking other drugs targeting cardiovascular risk control. The most clear design to examine the effects of the use of statins on exercise-mediated improvements in glucose homoeostasis and cardiovascular risk would be a doubleblind, placebo-controlled, randomized clinical trial. A disadvantage, however, would be that only subjects who were not on statins before the start of the study can be included and in daily life patients have usually been taking statins for quite some time even before they are advised to take physical exercise. Hence, we feel that the design of the present study provides a valuable and valid representation of what happens when subjects implement regular exercise in their daily lives, on top of any medication they are taking already. The drawback of our design is that the ST group is not homogeneous for some of the output parameters examined. The fact that we indeed do observe significant differences for the key outcome parameters, however, indicates the effects reported are strong enough to reach significance, even with the relatively small group size.

In conclusion, the present study shows in elderly males with moderate obesity that statin treatment did not inhibit exercise-induced improvements with respect to mitochondrial density and function. Rather, improvements in total cholesterol, insulin-stimulated lipolysis, insulin sensitivity, non-oxidative glucose disposal, metabolic flexibility and substrate oxidation were more pronounced and/or even exclusively detectable when exercise and statin use was combined. This study suggests that combining physical exercise training in subjects who tolerate statin treatment well under resting conditions may be at least as beneficial, and for some parameters even more beneficial, than exercise training exclusively. Thus the present findings indicate that the recently published guidelines of the American Diabetes Association [29] to prescribe statins to all T2D subjects over the age of 40 can be safely combined with previous guidelines on lifestyle interventions.

\section{AUTHOR CONTRIBUTION}

Ruth Meex performed the experiments and wrote the manuscript; Esther Phielix performed the experiments; Vera Schrauwen-Hinderling performed the MRS experiments; Esther Moonen-Kornips and Gert Schaart performed the analysis of the blood and plasma samples; and Patrick Schauwen and Matthijs Hesselink contributed to the discussions and reviewed/edited the manuscript prior to submission.

\section{ACKNOWLEDGEMENTS}

We gratefully acknowledge the valuable discussions with Dr R.P. Mensink and Dr J. Plot.

\section{FUNDING}

This work was supported by the Netherlands Organization for Scientific Research (NWO) [grant numbers 918.96.618 (VICI grant to P.S.), 917.66.359 (VIDI grant to M.K.C.H.)]. E.P. was supported by the Dutch Diabetes Research Foundation [grant number 2004.00.059].

\section{REFERENCES}

1 Snow, V., Aronson, M. D., Hornbake, E. R., Mottur-Pilson, C. and Weiss, K. B. (2004) Lipid control in the management of type 2 diabetes mellitus: a clinical practice guideline from the American College of Physicians. Ann. Intern. Med. 140, 644-649

2 Downs, J. R., Beere, P. A., Whitney, E., Clearfield, M., Weis, S., Rochen, J., Stein, E. A., Shapiro, D. R., Langendorfer, A. and Gotto, Jr. A. M. (1997) Design and rationale of the Air Force/Texas coronary atherosclerosis prevention study (AFCAPS/TexCAPS). Am. J. Cardiol. 80, 287-293 
3 Sigal, R. J., Kenny, G. P., Wasserman, D. H., Castaneda-Sceppa, C. and White, R. D. (2006) Physical activity/exercise and type 2 diabetes: a consensus statement from the American Diabetes Association. Diabetes Care 29, 1433-1438

4 Eldor, R. and Raz, I. (2009) American Diabetes Association indications for statins in diabetes: is there evidence? Diabetes Care. 32, (Supp. 2), S384-S391

5 Ghirlanda, G., Oradei, A., Manto, A., Lippa, S., Uccioli, L., Caputo, S., Greco, A. V. and Littarru, G. P. (1993) Evidence of plasma CoQ10-lowering effect by HMG-CoA reductase inhibitors: a double-blind, placebo-controlled study. J. Clin. Pharmacol. 33, 226-229

6 Paiva, H., Thelen, K. M., Van Coster, R., Smet, J., De Paepe, B., Mattila, K. M., Laakso, J., Lehtimaki, T., von Bergmann, K., Lutjohann, D. and Laaksonen, R. (2005) High-dose statins and skeletal muscle metabolism in humans: a randomized, controlled trial. Clin. Pharmacol. Ther. 78, 60-68

7 Phillips, P. S., Haas, R. H., Bannykh, S., Hathaway, S., Gray, N. L., Kimura, B. J., Vladutiu, G. D. and England, J. D. (2002) Statin-associated myopathy with normal creatine kinase levels. Ann. Intern. Med. 137, 581-585

8 Schick, B. A., Laaksonen, R., Frohlich, J. J., Paiva, H., Lehtimaki, T., Humphries, K. H. and Cote, H. C. (2007) Decreased skeletal muscle mitochondrial DNA in patients treated with high-dose simvastatin. Clin. Pharmacol. Ther. 81, 650-653

9 Sirvent, P., Mercier, J. and Lacampagne, A. (2008) New insights into mechanisms of statin-associated myotoxicity. Curr. Opin. Pharmacol. 8, 333-338

10 Draeger, A., Monastyrskaya, K., Mohaupt, M., Hoppeler, H., Savolainen, H., Allemann, C. and Babiychuk, E. B. (2006) Statin therapy induces ultrastructural damage in skeletal muscle in patients without myalgia. J. Pathol. 210, 94-102

11 Urso, M. L., Clarkson, P. M., Hittel, D., Hoffman, E. P. and Thompson, P. D. (2005) Changes in ubiquitin proteasome pathway gene expression in skeletal muscle with exercise and statins. Arterioscler. Thromb. Vasc. Biol. 25, 2560-2566

12 Thompson, P. D., Zmuda, J. M., Domalik, L. J., Zimet, R. J., Staggers, J. and Guyton, J. R. (1997) Lovastatin increases exercise-induced skeletal muscle injury. Metab., Clin. Exp. 46, 1206-1210

13 Meex, R. C., Schrauwen-Hinderling, V. B., Moonen-Kornips, E., Schaart, G., Mensink, M., Phielix, E., van de Weijer, T., Sels, J. P., Schrauwen, P. and Hesselink, M. K. (2009) Restoration of muscle mitochondrial function and metabolic flexibility in type 2 diabetes by exercise training is paralleled by increased myocellular fat storage and improved insulin sensitivity. Diabetes 59, 572-579

14 Kelley, D. E. and Mandarino, L. J. (2000) Fuel selection in human skeletal muscle in insulin resistance: a reexamination. Diabetes 49, 677-683

15 Frayn, K. N. (1983) Calculation of substrate oxidation rates in vivo from gaseous exchange. J. Appl. Physiol. 55, 628-634

16 Vanhamme, L., van den Boogaart, A. and Van Huffel, S. (1997) Improved method for accurate and efficient quantification of MRS data with use of prior knowledge. J. Magn. Reson. 129, 35-43
17 Naressi, A., Couturier, C., Castang, I., de Beer, R. and Graveron-Demilly, D. (2001) Java-based graphical user interface for MRUI, a software package for quantitation of in vivo/medical magnetic resonance spectroscopy signals. Comput. Biol. Med. 31, 269-286

18 Schrauwen-Hinderling, V. B., Kooi, M. E., Hesselink, M. K., Jeneson, J. A., Backes, W. H., van Echteld, C. J., van Engelshoven, J. M., Mensink, M. and Schrauwen, P. (2007) Impaired in vivo mitochondrial function but similar intramyocellular lipid content in patients with type 2 diabetes mellitus and BMI-matched control subjects. Diabetologia 50, 113-120

19 Schrauwen, P., Mensink, M., Schaart, G., MoonenKornips, E., Sels, J. P., Blaak, E. E., Russell, A. P. and Hesselink, M. K. (2006) Reduced skeletal muscle uncoupling protein-3 content in prediabetic subjects and type 2 diabetic patients: restoration by rosiglitazone treatment. J. Clin. Endocrinol. Metab. 91, 1520-1525

20 Wong, V., Stavar, L., Szeto, L., Uffelman, K., Wang, C. H., Fantus, I. G. and Lewis, G. F. (2006) Atorvastatin induces insulin sensitization in Zucker lean and fatty rats. Atherosclerosis 184, 348-355

21 Naples, M., Federico, L. M., Xu, E., Nelken, J. and Adeli, K. (2008) Effect of rosuvastatin on insulin sensitivity in an animal model of insulin resistance: evidence for statininduced hepatic insulin sensitization. Atherosclerosis 198, 94-103

22 Paniagua, J. A., Lopez-Miranda, J., Escribano, A., Berral, F. J., Marin, C., Bravo, D., Paz-Rojas, E., Gomez, P., Barcos, M., Moreno, J. A. and Perez-Jimenez, F. (2002) Cerivastatin improves insulin sensitivity and insulin secretion in early-state obese type 2 diabetes. Diabetes 51, 2596-2603

23 Szendroedi, J., Anderwald, C., Krssak, M., Bayerle-Eder, M., Esterbauer, H., Pfeiler, G., Brehm, A., Nowotny, P., Hofer, A., Waldhausl, W. and Roden, M. (2009) Effects of high-dose simvastatin therapy on glucose metabolism and ectopic lipid deposition in nonobese type 2 diabetic patients. Diabetes Care 32, 209-214

24 Traustadottir, T., Stock, A. A. and Harman, S. M. (2008) High-dose statin use does not impair aerobic capacity or skeletal muscle function in older adults. Age 30, 283-291

25 Thompson, P. D., Clarkson, P. and Karas, R. H. (2003) Statin-associated myopathy. JAMA, J. Am. Med. Assoc. 289, 1681-1690

26 Wassmann, S., Laufs, U., Muller, K., Konkol, C., Ahlbory, K., Baumer, A. T., Linz, W., Bohm, M. and Nickenig, G. (2002) Cellular antioxidant effects of atorvastatin in vitro and in vivo. Arterioscler. Thromb. Vasc. Biol. 22, 300-305

27 Forrester, J. S. and Libby, P. (2007) The inflammation hypothesis and its potential relevance to statin therapy. Am. J. Cardiol. 99, 732-738

28 Isley, W. L., Harris, W. S. and Miles, J. M. (2006) The effect of high-dose simvastatin on free fatty acid metabolism in patients with type 2 diabetes mellitus. Metab., Clin. Exp. 55, 758-762

29 American Diabetes Association (2010) Standards of medical care in diabetes: 2010. Diabetes Care 33 (Suppl. 1), S11-S61 


\title{
The use of statins potentiates the insulin-sensitizing effect of exercise training in obese males with and without Type 2 diabetes
}

\author{
Ruth C. R. MEEX*, Esther PHIELIX †, Vera B. SCHRAUWEN-HINDERLING †‡, \\ Esther MOONEN-KORNIPS* $†$, Gert SCHAART*, Patrick SCHRAUWEN $\dagger$ \\ and Matthijs K. C. HESSELINK* \\ * Department of Human Movement Sciences, NUTRIM School for Nutrition, Toxicology and Metabolism, Maastricht University \\ Medical Centre, Maastricht, The Netherlands, †Department of Human Biology, NUTRIM School for Nutrition, Toxicology and \\ Metabolism, Maastricht University Medical Centre, Maastricht, The Netherlands, and $\ddagger$ Department of Radiology, NUTRIM School \\ for Nutrition, Toxicology and Metabolism, Maastricht University Medical Centre, Maastricht, The Netherlands
}

\begin{tabular}{lll}
$\frac{\text { Table SI }}{\text { study }}$ & Statin use of the ST group subjects in the present \\
\hline Subject no. & Satin dose & Statin \\
\hline 1 & $1 \times 10 \mathrm{mg}$ & Atorvastatin \\
2 & $1 \times 20 \mathrm{mg}$ & Simvastatin \\
3 & $1 \times 5 \mathrm{mg}$ & Rosuvastatin \\
4 & $1 \times 10 \mathrm{mg}$ & Pravastatin \\
5 & $1 \times 40 \mathrm{mg}$ & Pravastatin \\
6 & $1 \times 40 \mathrm{mg}$ & Pravastatin \\
7 & $1 \times 5 \mathrm{mg}$ & Rosuvastatin \\
8 & $2 \times 30 \mathrm{mg}$ & Simvastatin \\
9 & $1 \times 10 \mathrm{mg}$ & Atorvastatin \\
10 & $1 \times 10 \mathrm{mg}$ & Atorvastatin \\
11 & $1 \times 5 \mathrm{mg}$ & Rosuvastatin \\
12 & $1 \times 40 \mathrm{mg}$ & Simvastatin \\
13 & $1 \times 20 \mathrm{mg}$ & Simvastatin \\
14 & $1 \times 40 \mathrm{mg}$ & Atorvastatin
\end{tabular}

